De Young, R. (2013). Environmental psychology overview.

In Ann H. Huffman \& Stephanie Klein (Eds.) Green

Organizations: Driving Change with IO Psychology. (Pp. 17-33) New York: Routledge.

2

\title{
Environmental Psychology Overview
}

\section{Raymond De Young}

Environmental psychology is a field of study that examines the interrelationship between environments and human affect, cognition, and behavior (Bechtel \& Churchman, 2002; Gifford, 2007; Stokols \& Altman, 1987). The field has always been concerned with both built and natural environments with early research emphasizing the former (Stokols, 1995; Sundstrom, Bell, Busby, \& Aasmus, 1996). However, as environmental sustainability issues became of greater concern to society in general, and the social sciences in particular, the field increased its focus on how humans affect, and are affected by, natural environments. The goals of this chapter are to introduce environmental psychology, explain how it emerged from the study of human-environment interactions and note how it has redefined what we mean by the terms nature and environment. Special note is made of humans as information-processing creatures and the implications this has for encouraging reasonable behavior under trying environmental circumstances. Finally, two pragmatic approaches to bringing out the best in people are presented.

In an effort to promote durable living on a finite planet, environmental psychology develops, and empirically validates, practical intervention strategies regardless of where the foundational science resides. Thus, the field considers as not useful the sometimes artificial distinction among the ficlds of cognitive, evolutionary, and social psychology. In so doing, environmental psychology incorporates the work of individuals who might not otherwise initially be identified with the field (consider, for instance, Cone \& Hayes, 1980; ( ieller, Winett, \& Everett, 1982; Katzev \& Johnson, 1987).

The same integrative approach applies to the level of analysis and scale of intervention. The field explores individual and collective level behavior and seeks interventions that work at all of these scales. In fact, this is one 
of the strengths of the field. It has always been problem-oriented, using, as needed, the theories, methods, and findings of related disciplines (e.g., anthropology, biology, ecology, psychology, sociology) and the professional schools (e.g., education, public health, social work, urban planning). In this pragmatism, environmental psychology well symbolized one of Kurt Lewin's better known quotes, "There is nothing so practical as a good theory" (1951, p. 169).

More recently, the applied fields of conservation psychology (Clayton \& Myers, 2009; Saunders \& Myers, 2003) and ecopsychology (Doherty, 2011) have emerged to understand and resolve issues related to human aspects of conservation of the natural world. The former initiative merges the insights, principles, theories, and methods used by conservation biology and a wide range of psychology subfields. The latter initiative is also broad-based and includes a therapeutic approach to enhancing peopleenvironment interactions and personal wellbeing. Both maintain a rich network of researchers and practitioners who share the goals of creating durable behavior change at multiple levels, promoting an environmental ethic and maintaining harmonious human-nature relationships.

Today the fields of environmental psychology, conservation psychology and ecopsychology are helping society to form an affirmative response to emerging environmental and natural resource constraints. This is a grand challenge since the response must plan for, motivate, and maintain environmental stewardship behavior through a period of significant energy and resource descent. The initial focus is to pre-familiarize ourselves with living well within the limits of natural ecosystems (De Young \& Princen, 2012).

\section{WHAT IS MEANT BY ENVIRONMENT}

Over its nearly half-century of research and practice, the field of environmental psychology has expanded both the definition of what is nature and what is environment. The field still studies to good effect built settings (e.g., wayfinding in subways systems, navigating in distracting environments). But as its research interests and methods matured, the field found the distinction between built and natural settings often unhelpful and unnecessarily limiting.

Clearly, urban settlements devoid of all forms of nature, if they ever existed, are infrequent to the point of being irrelevant to most people. Likewise, pristine wilderness, untouched by human hands, is rare. Environmental psychology understands that humans know nature, in its many forms, as intermixed with built elements. This melding can be seen in urban parks and waterfronts, zoos and aquaria, backyard and meditation gardens, exurban bikeways and wetland boardwalks, fence-lined country lanes and blazed mountain trails. Nature is nearby and viewable from almost any window. Even when not nearby, nature usually contains signs that others have been there before.

Here too is another discovery of environmental psychology. Something counts as nature even if it does not contain DNA. The wind through the leaves, the flow of water, the smell of a spring rainstorm, moonrises, and ocean waves are all experienced as part of nature and have potential psychological effect.

But a perhaps more fundamental insight of environmental psychology comes from its broad conceptualization of what constitutes an environment. It borrows from cognitive psychology the notion that all environments are patterns of information and that people are fundamentally information-processing organisms, deeply motivated to remain informationally, and thus environmentally, competent. In their pursuit of goals, humans need both to understand current environmental patterns and to continuously expand their proficiency by exploring and learning from new patterns.

The shift here is subtle. The focus is not on specific groups, single personality traits or particular psychological mechanisms. Rather, environmental psychology explores the environmental context of human behavior and wellbeing. This context might be physical (e.g., home, office, park), social, conceptual (e.g., design, narrative), vast or small. It might be known from direct experience or from becoming pre-familiarized with something not yet present, something that might be experienced only indirectly though stories or simulations. The latter is possible because one of the astonishing effects of our information-processing capability is our being able to feel at home in a place we do not yet inhabit.

One additional aspect of the subtle shift in perspective reveals a key premise of environmental psychology. To understand behavior we need to study more than just the context of that behavior (i.e., the environment) and more than just the traits and goals of the individual or group whose behavior is of interest. We can understand, and perhaps influence, 
behavior more effectively by studying the interaction of context and traits, environmental affordances and cognitive inclinations, settings, and goals. It is in the interactions that we can understand the origins of reasonable (and unreasonable) human behavior.

\section{ENCOURAGING AND SUPPORTING REASONABLE PEOPLE}

Unreasonable behavior (e.g., being irresponsible, uncooperative, intolerant, unpleasant) seems to be proliferating in fast-paced, high-consuming industrialized societies. One might conclude that such behavior is humans' standard operating condition. Fortunately, many years of psychological research shows this conclusion to be wrong. Environmental psychologists Rachel Kaplan and Stephen Kaplan suggest that the difference between reasonable and infuriatingly unreasonable behavior may be partly explained by the environments in which people find themselves. To this observation that the context of behavior makes a diffcrence, they note two other key facts: that humans have a remarkable facility to process information, and that information and affect are in a close adaptive relationship with each other. Taken together, these provide the basic premise of the reasonable person model-namely, that people are more likely to be reasonable and cooperative in environments that support their informational needs (Kaplan and Kaplan, 2003, 2009).

Before outlining these informational needs, it is useful to make clear what is meant by information. Information, much more than money or social interaction, is the foundation of our lives. As Kaplan, R. (1995) points out, humans are information-based organisms: “... we love it and hate it, we collect it and trade it, we hide it and leak it, we are overwhelmed by it and addicted to it. Information is central to our functioning, to our personal sense of esteem, to our interdependencies, to the basis for distinguishing ourselves from others-for better and for worse." Information surrounds us. While much information comes from spoken and written material, the environment in all its many forms conveys vast amounts of information (e.g., the behavior of others, the array of objects we encounter, the events that unfold).

The reasonable person model focuses on the interrelationships among three major domains of human informational needs. First is the need for building mental models. These models address the simultaneous human needs for understanding and exploration. The way in which the environment supports or hinders this need affects everything from behavioral competence to psychological wellbeing. The second domain is about becoming effective and also includes two elements: being clear-headed enough to be capable of responding appropriately to the profusion of information around us, and the sense of competence that comes from knowing what may be possible and how to act. Being confused or incompetent does not bring out the best in people; thus restoring and maintaining mental vitality and proficiency is essential to supporting reasonable behavior. Finally, there is the need for meaningful action, a need to be an active part of the world around us, to be respected for our role and to do things that matter in the long run. While closely aligned with our inclinations to be helpful, this need can also be fulfilled by the many behaviors where the social relevance may not be obvious or immediate. Each domain can be explored independently. However, as a practical matter they are highly interrelated. Consider how hard it is to take meaningful action without first understanding the situation, how being clear-headed can make our behaviors much more effective, and how exploring natural settings can restore our mental vitality.

\section{Model Building}

A mental model is a highly simplified version of reality that humans store in their head and use to make sense of things, to plan, to evaluate possibilities, in short to manage all everyday functioning. These portable models store the knowledge gained from the many experiences people have and are the basis for making decisions. They are foundational to all knowing and acting and people find it useful to be constantly building and testing them against reality. One element of model building, understanding, can be achieved through formal learning. More commonly, however, understanding is gained through direct and indirect experience. The other element of model building, exploration, is about moving about in a space or a concept to learn more about it. Such exploration can take place in the physical world, or virtually, or entirely in one's mind. It can be about the present or about a future time and place. Team-based problem solving and brainstorming are group-based exploration although the models built are contained in the heads of the individual team members; this 
seems like an obvious observation until we realize that the stored models may not be identical, thus affecting group behavior. Satisfying the need for exploration allows humans to expand their mental models, increasing their understanding.

Being an information-based animal, our survival requires the mental capability to recognize what is happening and to predict what might happen next while there is still time to take suitable action. This need places a high priority on exploration. Yet, while we are motivated to learn more about the environment, we must never go so far that our mental models no longer sufficiently understand the situation. While we are eager to explore, so too are we quick to return to what is familiar. Simultaneously, we need to make sense of our present situation while also acquiring, at our own pace, information that is relevant to our current and future concerns. Thus exploration, if pursued close to the familiar, becomes a powerful means of expanding our understanding.

One of the fascinating aspects of human nature builds upon the role familiarity plays in our cognition. In conversations about behavior change, it is often claimed that people anchor to the status quo and are immune to scientific arguments. One might infer that, if true, this would pose a serious problem for behavior change efforts. After all, to deal with the urgent environmental problems being faced, people may be called upon to make far-reaching changes away from the status quo, toward an unfamiliar life pattern, some promoted by abstract scientific arguments alone. Fortunately, however, the issue here is not a status quo bias but a familiarity bias. A familiarity bias is based on our mental model of a situation and thus mirrors the strengths and weaknesses of our current understanding. This provides great hope since mental models can be formed and altered in a large variety of ways.

\section{Becoming Effective}

This domain is about the need to be clear-headed and competent so as to be able to achieve our goals. It is here that we can clearly see the constraints on and limits of human information processing.

First and foremost, becoming effective is about achieving clarity in our thinking by maintaining our mental vitality. This is a formidable challenge since handling all the information we crave, as well as dealing with the onslaught of unbidden information, easily leads to being overwhelmed and mentally exhausted. Yet, while some environments can cause a loss of mental vitality, others can provide for its restoration.

Attention restoration theory (Kaplan, S., 1995, 2001) explains this apparent contradiction. This theory builds on the distinction between two forms of attention called fascination and directed attention. The former, fascination, is involuntary attention; it requires no significant effort and is not under volitional control. Fascination is experienced when, out of innate interest or curiosity, certain objects or processes effortlessly engage our thoughts. William James provided a list of such innately fascinating stimuli: "strange things, moving things, wild animals, bright things, pretty things, blows, blood, etc. etc. etc." (1892/1985). The potential significance of such objects argues for why this form of attention does not fatigue; it is adaptive that such things continue to rivet our attention even if encountered repeatedly.

In contrast to fascination, the capacity to direct attention requires major effort. This directed mental effort is essential for remaining effective in the many situations that lack fascination. In order to contemplate important yet uninspiring objects and processes, we must inhibit competing or peripheral yet perhaps more interesting thoughts and stimuli. Such inhibition allows us to carry out an important plan despite the presence of diversions, listen closely while beset by noise, and feel compassion for and help others despite our own unmet needs. The adaptive significance of directed attention is enormous. Behaviorally, the ability to hold the immediate environment at bay permits humans to insert their own intentions between stimulus and response. Cognitively, this ability allows us to concurrently run multiple models in our head without undue confusion, contemplate alternate explanations for an observation and consider multiple responses.

Unfortunately the capacity to voluntarily direct our attention is finite. When under constant demand our ability to control the inhibitory process tires, resulting in a condition called directed attention fatigue. This mental state greatly reduces our effectiveness. The signs of this mental fog are many: irritability and impulsivity that results in regrettable utterances, impatience that has us quickly jumping to ill-formed conclusions, and distractibility that results in tasks being left unknowingly unfinished (De Young, 2010).

In order to restore the capacity to direct attention, it is necessary to seek out environments that require little of this finite resource or that use other means of maintaining mental focus. Thus recovery can be achieved by pursuing activities that rely heavily on involuntary fascination. As fascination 
is engaged, the need for directed attention is greatly reduced, which thereby allows for its recovery. Thus an essential feature of restorative environments is their ability to elicit fascination. In principle there are many types of restorative environments. However, research has repeatedly highlighted the role of time spent in natural settings in the effort to remain mentally effective (Berman, Jonides, \& Kaplan, 2008, Frumkin 2001, Herzog, Black, Fountaine, \& Knotts, 1997, Kaplan \& Kaplan, 1989, 2005).

Tending to our mental vitality is essential for achieving clear-headedness. Becoming fully effective, however, requires a second element, which involves achieving and maintaining a sense of competence. Feeling competent depends on knowing how things work in the world, knowing what is possible and appropriate, and having the skills that match the challenges we face. While there is a contentment from being competent, we are also intrinsically motivated by the process of improving and extending the competence we already have.

\section{Meaningful Action}

Information can be a source of insight, comfort, and motivation. It also can be fascinating. All too often, however, the information we receive leaves us feeling overwhelmed or feeling that there is nothing we can do to put things right. Such feelings of helplessness, not surprisingly, are demoralizing (Seligman, 1975), hardly a state that leads to reasonable behavior.

Meaningful action, in contrast, is the opportunity to make a useful contribution to a genuine problem. It may involve being effective at a large scale (e.g., the choice of livelihood, a lifelong struggle for environmental justice or food security) but perhaps more often it involves actions at a more modest level (e.g., participating in a stewardship activity, community involvement, voting). The meaningfulness experienced is less about the scale of the effort and more about deriving a sense of making a difference, being listened to and respected, and feeling that we have a secure place within our social group. Reasonable behavior is more likely when people feel that they are needed and that their participation matters. A number of studies indicate that doing something judged worthwhile or making a difference in the long run are primary motives underlying voluntary environmental stewardship behavior (Grese, Kaplan, Ryan, \& Buxton, 2000, Miles, Sullivan, \& Kuo, 2000). In these studies, the notion of meaningful action emerged as one of the most significant sources of satisfaction.
As mentioned earlier, the elements of the reasonable person model are highly interrelated. Perceiving a sense of competence and achieving respect are deep founts of meaningful action. Just as people who feel confused, mentally exhausted or helpless are rarely at their best, when these concerns are addressed, people are much more likely to be reasonable and cooperative. In short, bringing out the best in people is more likely when the environment supports understanding and exploration, develops competence, promotes a clear head, and enables meaningful action.

\section{TRANSITIONING TO SUSTAINABLE LIVING}

As we contemplate the changes that will be needed to address the many environmental issues being faced (e.g., climate disruption, energy descent, environmental injustice, soil depletion), it is heartening that the reasonable person model supports the notions that humans seek meaningfulness more than novelty, that they benefit more from developing a sense of competence, clarity, and mental vitality than from pursuing convenience or hedonic pleasure, and that the mind is better adapted to exploring, problem solving, and sense making than it is to affluence.

The transitions needed to live sustainably within biophysical limits will dramatically alter the context and content of everyday behavior. Surprising to some, the coming downshift may actually stimulate people's natural inclinations to explore and understand, and to pursue acts of meaning. Thus, the transition we will need to make will create many of the very conditions that, environmental psychology research shows, support reasonable behavior.

However, to increase the probability of success, we must encourage experiments on a multitude of options. Citizen and environmental experts alike should constantly tinker with new institutional forms, metaphors, norms, and principles. Perhaps most importantly, we must each become behavioral entrepreneurs, exploring new behaviors and new ways to combine old behaviors. Perhaps a behavioral aesthetics is possible, a way to live our daily lives as a work of art as we adapt-in-place. We may be facing a materially simpler life but it may be possible to live with beauty.

Although our current analytical tools can help make sense of the past (e.g., how did we get to this state of climate disruption and energy descent) 
and the present (e.g., what is the nature of our environmental predicament), and can extrapolate recent trends into the future, they cannot determine which paths into the future will prove more useful. For this we must adopt an adaptive, experimental approach. Our problem solving must seek a plurality of solutions, not the one right solution or the magic elixir. Emerging plans, policies, and procedures should be viewed as hypotheses in constant need of reality testing. Or, as author and community organizer Pat Murphy puts it, we need to "make a lot of mistakes quickly" (quoted in Cobb, 2009). The "quickly" part of this suggestion comes from the concern that climate disruption and energy constraints are happening at a frequency and intensity thought to be, until recently, many decades away. The anticipation of mistakes comes from a humility that echoes the insights of Meadows, Randers, and Meadows (2004) who argue that in our current state of biophysical overshoot we need to find the right balance between environmental urgency and patience. Achieving this balance will require humility, honesty, and clear-headedness.

\section{THE POWER OF SMALL EXPERIMENTS}

To the extent that the response to an environmental dilemma must be place-based, it becomes inappropriate to rely solely upon universal interventions. In fact, the need for a localized response diminishes the effectiveness of outside solutions altogether. Participants struggling to form a localized response will benefit only slightly from generic instructions. And they certainly will not take kindly to being informed by outside practitioners about how they must behave.

In such situations a competent and situation-aware practitioner will see that his or her role has changed. This role becomes suggesting guidelines for how participants might craft their own response and then being prepared to answer the questions that naturally arise from the resulting effort. The urgency and dramatic consequences remain, but the process of responding has changed.

An approach to behavior change under conditions of urgency, great environmental uncertainty, and grave stakes, yet with a need for place-based sensitivity, might start with small steps. As anthropologist and political scientist James Scott advises with respect to interventions for economic devel- opment, "Prefer wherever possible to take a small step, stand back, observe, and then plan the next small move" (Scott, 1998, p. 345). Scott's suggestion follows, in part, the small-experiment approach to environmental problem solving outlined by Irvine and Kaplan (2001; see also Kaplan, Kaplan, \& Ryan 1998). Small experiments is a framework for supporting problem solving that is based on the innate inclinations that are at the core of the reasonable person model, particularly the building and sharing of mental models. It supports innovation, maintains local relevance and experimental validity all while promoting rapid dissemination of findings. It is also in contrast to the large-scale, bigger-is-better approach that dominates so much of research these days; an experiment need not be intimidating to be useful.

The small experiment framework can help people who are not trained scientists to validate what works in their locality. But while the involvement of the non-expert is possible, is it more likely under this approach? To be effective, the small-experiment framework would need to create greater individual and group engagement.

To enhance engagement, the small experiment framework carefully manages the scale of the activity. Picking the appropriate scale is a crucial step. It was Weick's (1984) insight that people anchor around the scale and structure of the initial problem definition and start to work on solutions that are only at that same scale or structure. If we cast the problems faced as being at a large scale, as is often the case with environmental issues, then it is hard to imagine anything but a large-scale solution sufficing. Furthermore, imagining that solutions as being of only one fundamental type (e.g., political, economic) unnecessarily limits what people can offer. Large-scale problems may seem to demand large-scale solutions, yet the scale of the problem need not dictate the scale of the solution. And not all environmental problems work out to be problems of policy or economics and thus not all solutions need be political or economic in nature.

There are both ethical and motivational issues at work in the small experiment framework. The careful attention to the scale of problems and solutions is well matched to the ancient ethical teaching that while "it is not your responsibility to finish the work [of perfecting the world], you are not free to desist from it either." A key element of small experiments is that people need only focus on what they are better prepared to handle. Others will handle that which they are positioned to solve.

The motivational effect likely comes from the intrinsic satisfaction derived from developing, displaying, and maintaining competence (De 
Young, 1996). Since success at a smaller scale can result in an empowering sense of competence, this may result in people being more willing to continue or re-start their problem-solving efforts at a later date or in a different setting (Monroe, 2003). Social benefits also may emerge from keeping the scale small; trust is easier to build and may prove useful when efforts must be repeated.

Small experiments are going on all the time. They are often the basis of stories told by at-home tinkerers, dedicated gardeners, office problem solvers and innovative teachers. They are part of team efforts where experts and citizens combine and apply their talents and knowledge to a problem of mutual concern. Consider also the many pilot programs, field tests, demonstration sites, and trial runs regularly reported in both popular and scientific publications.

Small experiments are so common that they may seem inconsequential to the casual observer, yet they can be a powerful means of behavioral entrepreneurship. Their effectiveness can be enhanced by following a few simple guidelines.

\section{Scale and Expectation}

While already an integral aspect of small experiments, smallness can be understood in a variety of ways. Keeping the physical scope small is obvious. Others include keeping the breadth of exploring small and the timespan short as well as involving only a small number of people as participants or respondents. The experiment can also be tentative, tried out for a limited time or on a limited basis. These guidelines help keep the costs of project initiation and management low. So too should expectations be kept in check. The findings of small experiments are unavoidably imperfect and incomplete. Yet small too are the consequences of failure; failure is always a possibility if an experiment is genuine. Nonetheless, as Irvine and Kaplan document (2001), findings from a modest enterprise may prove extraordinarily useful and have broad effects.

\section{Goal and Focus}

Keep the focus on only one specific and well-defined problem. While it may be okay to start exploring before having absolutely everything in place, it is essential to first have a clear and concise question. Such a question motivates the effort and makes it easier to avoid distractions no matter how fascinating they may be. Spending too little time on figuring out what you hope to learn is the surest way to fail. Anticipating what you would like to be able to say at the end is an excellent way of formulating your initial question. Here too, modest expectations may be a helpful guide; the aim of the small experiment is to identify reasonable solutions, preferably a multitude of them. The goal is not a search for the ideal answer.

\section{Tracking and Record Keeping}

Empirical research, at its core, involves being attentive to what is going on. Whether formal or informal information gathering is used, the objective is to systematically learn what worked and what did not. At the immediate time frame and at the local level, the tracking allows for feedback to the participants. In situations involving behavior change, rapid feedback allows for self-correction; people can learn how the specific choices they made affected the outcome. Without such feedback behavior cannot be changed is a pragmatic and productive way. Over the longer time frame, the information recorded informs next steps and may provide the basis for developing generalizations that might be useful to share with others. Once again, modest expectations can play a role in deciding the amount and form of information to be tracked. The intent is to collect only enough information to allow for feedback and inference; too little information precludes useful learning, but too much information can paralyze the analysis process. Easy to gain information is always preferred in modestly funded small experiments.

\section{Dissemination and Communication}

Sharing the successes of a small experiment is an excellent way to let participants know that their efforts mattered. It is also an opportunity to validate the correctness of the proposed changes for the local people who were not directly involved in the small experiment. Finally, communicating with people at a distance may inform and motivate other small experiments; successes in one locality become plausible options to explore elsewhere, while communicating about failures instills caution. The form of 
communication used can vary with the circumstances. Newsletters, newspaper articles, and presentations at an open-house can work well locally while professional presentations, blogs, journals, and magazines can help with wider dissemination. But regardless of the outlet used, clear, concrete, vivid, and engaging language will help to familiarize others with the findings.

It is noteworthy that nothing in these guidelines restricts small experiments to taking only small steps or to a slow discovery process. A behavior change process called adaptive muddling stresses this subtle but important issue (De Young \& Kaplan, 1988). Adaptive muddling adds one important aspect to the small experiment framework. A stability component is used to reduce the costs of failure for the individuals involved. It also makes highly improbable unchecked and disorienting change. With a safety net in place, people need not privilege the status quo by investigating only marginal behavior change. Far-reaching change can be both contemplated and explored. The scale of the experiment may be small but adaptive muddling supports people exploring, and thus pre-familiarizing themselves with life-changing adaptations. Since this modification to the small experiment framework makes the exploration process less intimidating, discovery can occur more quickly as more people become engaged. Furthermore, while the impact from any one group's change may be modest, this process supports simultaneously exploring, and sharing the results of, many changes at once, each drawing on the knowledge and experience people already possess.

Some people may argue that the small experiment framework is a renamed version of the experimenting society proposed by Campbell (1981). The experimenting society suggests that social programs should be designed and implemented as experiments with a built-in evaluation process. However, in Campbell's version, the evaluation is a formal process, one conducted by social scientists using meticulous, expertly designed trials followed by rigorous statistical analyses. Furthermore, the results are intended for use by governmental policy makers and, perhaps, for later publication.

The small experiments approach uses the concept of an experiment in a much less restricted sense. The analysis involved in such experiments is less formal and more compatible with immediate needs and local capabilities. Online accounts, reports by participants or visits by interested individuals would be appropriate additions to whatever fórmal record keeping is employed. The more expert-based framing of an experiment used by Campbell makes his approach less likely to be tried by, and the results less accessible to, non-experts.

The small experiment framework is a quick and simple way to promote behavior change that is compatible with what environmental psychology has learned about human nature. Such an approach can enable people to build mental models that allow them to view the urgent and serious environmental issues they face in terms of challenge and possibility rather than inevitability and despair.

\section{HUMANS AS ENGAGED AND PURPOSEFUL}

There is still much to be learned about human-environment interaction. Nonetheless, the reasonable person model, and the related tools of small experiments and adaptive muddling, provides a context for creating interventions that bring out the best in people. Together they provide a framework for working with people in ways that fulfill a variety of innate inclinations: to explore, to understand, to enhance competence, to be part of a solution, and to pursue meaningful goals.

This framing recognizes humans as active, purposive beings, not as mere recipients of the information patterns generated by environments or experts. But of all these innate inclinations, none is more central than model building. In an effort to explore and understand, people are constantly either building models of their experiences and the environment, or using their existing mental models to effectively function in an environment. There is an affective and motivational aspect here as well, but it does not involve putting people into a positive affective state beforehand. People deeply care about the model-building process. They gain intrinsic satisfaction from exploring, building, and sharing mental models. They are pained by a process that results in confusion or boredom. Thus affect is fundamental to, but derived from, the process of learning and knowledge transfer.

In short, environmental psychology has discovered that by being attentive to the innate need and capability of people to build new mental models and test old ones, we can enhance their knowledge acquisition and wellbeing. We can also better manage and leverage behavior change and thus, quite possibly, repair the world. 


\section{REFERENCES}

Bechtel, R. B., \& Churchman, A. (Eds.) (2002). Handbook of environmental psychology. New York, NY: Wiley.

Berman, M. G., Jonides, J., \& Kaplan, S. (2008). The cognitive benefits of interacting with nature. Psychological Science, 19, 1207-1212.

Campbell, D. T. (1981). Introduction: Getting ready for the experimenting society. In L. Saxe and M. Fine (Eds.), Social experiments: Methods for design and evaluation (pp. 41-62). Beverly Hills, CA: Sage.

Clayton, S., \& Myers, O. E., Jr. (2009). Conservation psychology: Understanding and promoting human care for nature. New York, NY: Wiley-Blackwell.

Cobb, K. (2009, March). We must make a lot of mistakes quickly. Resource Insight. Retrieved May 30, 2012, from http://resourceinsights.blogspot.com/2009/03/we-must-makelot-of-mistakes-quickly.html.

Cone, J. D., \& Hayes, S. C. (1980). Environmental Problems/Behavioral Solutions. Monterey, CA: Brooks/Cole.

De Young, R. (1996). Some psychological aspects of reduced consumption behavior: The role of intrinsic satisfaction and competence motivation. Environment and Behavior, $28,358-409$.

De Young, R. (2010). Restoring mental vitality in an endangered world. Ecopsychology, 2, $13-22$.

De Young, R., \& Kaplan, S. (1988). On averting the tragedy of the commons. Environmental Management, 12, 283-293.

De Young, R., \& Princen, T. (2012). The localization reader: Adapting to the coming downshift. Cambridge, MA: MIT Press.

Doherty, T. J. (2011). Psychologies of the environment. Ecopsychology, 3, 75-77.

Frumkin, H. (2001). Beyond toxicity: Human health and the natural environment. American Journal of Preventative Medicine, 20, 234-240.

Geller, E. S., Winett, R. A., \& Everett, P. B. (1982). Preserving the environment: New strategies for behavioral change. New York, NY: Pergamon Press.

Gifford, R. (2007). Environmental psychology: Principles and practice (4th ed.). Canada: Optimal Books.

Grese, R. E., Kaplan, R., Ryan, R. L., \& Buxton, J. (2000). Psychological benefits of volunteering in stewardship programs. In P. H. Gobster and R. B. Hill (Eds.), Restoring nature: Perspectives from the social sciences and humanities (pp. 265-280). Washington, D.C: Island Press.

Herzog, T. R., Black, A. M., Fountaine, K. A., \& Knotts, D. J. (1997). Reflection and attentional recovery as distinctive benefits of restorative environments. Journal of Environmental Psychology, 17, 165-170.

Irvine, K. N., \& Kaplan, S. (2001). Coping with change: The small experiment as a strategic approach to environmental sustainability. Environmental Management, 28, $713-725$.

James, W. (1982/1985). Psychology: The briefer course. Notre Dame, IN: University of Notre Dame Press.

Kaplan, R. (1995). Informational issues: A perspective on human needs and inclinations. In G. A. Bradley (Ed.), Urban forest landscapes: Integrating multidisciplinary perspectives (pp. 60-71). Seattle, WA: University of Washington Press.

Kaplan, R., \& Kaplan, S. (1989). The experience of natture: A psychological perspective. New York, NY: Cambridge University Press.
Kaplan, R., \& Kaplan, S. (2005). Preference, restoration, and meaningful action in the context of nearby nature. In P. F. Barlett (Ed.), Urban place: Reconnecting with the natural world (pp. 271-298). Cambridge, MA: MIT Press.

Kaplan, R., Kaplan, S., \& Ryan, R. L. (1998). With people in mind: Design and management of everyday nature. Washington, DC: Island Press.

Kaplan, S. (1995). The restorative benefits of nature: Toward an integrative framework. Journal of Environmental Psychology, 15, 169-182.

Kaplan, S. (2001). Meditation, restoration and the management of mental fatigue. Environment and Behavior, 33, 480-506.

Kaplan, S., \& Kaplan, R. (2003). Health, supportive environments, and the reasonable person model. American Journal of Public Health, 93, 1484-1489.

Kaplan, S., \& Kaplan, R. (2009). Creating a larger role for environmental psychology: The Reasonable Person Model as an integrative framework. Journal of Environmental Psychology, 29, 329-339.

Katzev, R. D., \& Johnson, T. R. ( 1987). Promoting energy conservation: An analysis of behavioral research. Boulder, CO: Westview Press.

Lewin, K. (1951). Field theory in social science: Selected theoretical papers. D. Cartwright (Ed.). New York, NY: Harper \& Row.

Meadows, D. H., Randers J., \& Meadows, D. L. (2004). Tools for the transition to sustainability. In Limits to growth: The 30-year update (pp. 265-284). White River Junction, VT: Chelsea Green Publishing Company

Miles, I., W. C. Sullivan, \& Kuo, F. E. (2000). Psychological benefits of volunteering for restoration projects. Ecological Restoration, 18, 218-227.

Monroc, M. (2003). Two avenues for encouraging conservation behaviors. Human Ecology Review, 10, 113-125.

Saunders, C., \& Myers, O. E., Jr. (Eds.) (2003). Conservation psychology [Special edition]. Human Ecology Review, 10(2).

Scott, J. C. (1998). Seeing like a state: How certain schemes to improve the human condition have failed. New Haven, CT: Yale University Press.

Seligman, M. E. P. (1975). Helplessness: On depression, development, and death. San Francisco, CA: Freeman.

Stokols, D. (1995). The paradox of environmental psychology. American Psychologist, 50, $821-837$.

Stokols, D., \& I. Altman (Eds.) (1987). Handbook of environmental psychology ${ }_{2}$ Volumes 1 and 2. New York: John Wiley and Sons.

Sundstrom, E., Bell, P. A., Busby, P. L., \& Aasmus, C. (1996). Environmental psychology 1989-1994. Annual Review of Psychology, 47, 482-512.

Weick, K. (1984). Small wins: Redefining the scale of social problems. American Psychologist, 39, 40-49. 